vigorous immune destruction of hepatocytes in women, and they are less able than men to suppress this reaction once alcohol is withdrawn. We have suggested that a similar type of mechanism may be important in the pathogenesis of chronic active hepatitis. $^{3+}$ Thus, while every effort must be made to recognise alcohol abuse at an early stage, and to encourage abstinence, these measures may still be inadequate to prevent the progression of liver disease in certain susceptible individuals and particularly in women.

We are grateful to the Medical Research Council for their continued support and to the medical records department for their help with this investigation.

\section{References}

British Medical fournal, 1972, 4, 625

2 Jain, S, Paton, A, and Wansbrough-Jones, M H, Midland Medical Review, 1973, 9, 13.

${ }^{3}$ Stone, W D, Islam, N R K, and Paton, A, Quarterly fournal of Medicine, $1968,37,119$.

${ }^{4}$ Hodgson, H J F, and Thompson, R P H, Lancet, 1976, 2, 118.

5 Scheuer, P J, in Liver Biopsy Interpretation, 2nd edn. London, Ballière Tindall, 1973.

${ }^{6}$ Edmonson, H A, et al, Annals of Internal Medicine, 1963, 59, 646.

- Mancini, G, Carbonara, A D, and Heremans, J F, Immunochemistry, $1965,2,235$.

${ }^{\circ}$ Roitt, T M, and Doniach, D, Manual of Autoimmune Serology. Geneva, World Health Organisation, 1969.

${ }^{9}$ Eddleston, A L W F, et al, Gut, 1969, 10, 711.

10 Brunt, P W, et al, Gut, 1974, 15, 52.
11 Annual Abstracts of Statistics, London, HMSO, 1975.

12 Cartwright, A K J, Shaw, S J, and Spratley, T A, Designing a Comprehensive Community Response to Problems of Alcoholic Abuse. London, Bethlem Royal and Maudsley Hospital, 1975.

13 Sclare, A B, Fournal of Alcoholism, 1975, 10, 134.

14 Spain, D M, American fournal of Clinical Pathology, 1945, 15, 215.

${ }^{15}$ Wilkinson, P, Santamaria, J N, and Rankin, J G, Australian Annals of Medicine, 1969, 18, 222.

${ }^{16}$ Pequingot, G, et al, Review of Alcoholism, 1974, 20, 191.

1: Forshaw, J, British Medical fournal, 1972, 4, 608.

18 Lelbach, W K, Acta Hepatosplenologica, 1966, 13, 321.

${ }^{19}$ Lelbach, W K, Acta Hepatosplenologica, 1967, 14, 9.

20 Rubin, E, Lieber, C S, Clinics in Gastroenterology, 1975, 4, 247.

21 Korsten, M A, et al, New England Fournal of Medicine, 1975, 292, 386.

2:2 Cochrane, A M G, et al, Gastroenterology, 1977, 72, 918.

23 Zetterman, R K, Luisada-Opper, A, and Leevy, C M, Gastroenterology, 1976, 70, 382.

24 Bailey, R J, et al, British Medical fournal, 1976, 2, 727.

25 Galbraith, R M; et al, British Medical fournal, 1974, 3, 604

26 Sherlock, S, in Diseases of the Liver and Biliary Systems, 5th edn. Oxford, Blackwell Scientific Publications, 1975.

$2:$ Iniger, D R, Annals of Clinical Research, 1976, 8, 174.

$2 \times$ Simjee, A E, et al, Gut, 1975, 16, 871.

29 Krasner, N, et al, Gut, 1976, 17, 390.

30 Galambos, J T, in Progress in Liver Diseases, vol 4, ed H Popper and F Schaffner. New York, Grune and Stratton, 1972.

${ }^{31}$ Powell, W J, and Klatskin, G, American fournal of Medicine, 1968, 44, 406.

32 Tygstrup, N, and Juhl, E, in Alcohol and the Liver, ed W Gerok, K Sickinger, and $\mathrm{H} \mathrm{H}$ Hennekeuser. Stuttgart, F K Schattauer, 1971.

${ }^{33}$ Sherlock, S, Brunt, P, and Scheuer, P J, in Alcohol and the Liver, ed W Gerok, K Sickinger, and $\mathrm{H} \mathrm{H}$ Hennekeuser. Stuttgart, F K Schattauer, 1971.

${ }^{34}$ Eddleston, A L W F, and Williams, R, Lancet, 1974, 2, 1543.

(Accepted 6 April 1977)

\title{
Study of fatal bone marrow depression with special reference to phenylbutazone and oxyphenbutazone
}

\author{
WILLIAM H W INMAN
}

British Medical fournal, 1977, 1, 1500-1505

\begin{abstract}
Summary
The histories of 269 patients whose death certificates did not mention a drug as the cause of aplastic anaemia or agranulocytosis were investigated. Eighty-three deaths were probably caused by drugs, the most common cause of aplastic anaemia being treatment with phenylbutazone ( 28 deaths) and oxyphenbutazone (11 deaths). Thirteen out of 17 deaths from agranulocytosis were attributed to co-trimoxazole treatment. A separate survey of general practitioners' prescriptions enabled the mortality to be estimated. With the addition of one death due to oxyphenbutazone and four deaths due to phenylbutazone that were reported independently to the committee, the mortality from oxyphenbutazone was 3.8 per 100000 and from phenylbutazone 2.2 per 100000 . With phenylbutazone the rates varied from under 1 death per 100000 for men aged under 65 years to 6 per 100000 for women aged 65 and over. Small numbers precluded estimates for oxyphenbutazone in these subgroups, although a similar trend was suggested. No particular
\end{abstract}

Committee on Safety of Medicines, London EC2A 1PP

WILLIAM H W INMAN, MRCP, MFCM, principal medical officer indication for treatment seems to carry a higher risk, the main concern being the use of these two drugs in elderly patients.

\section{Introduction}

In 1964 the Committee on Safety of Drugs (now Committee on Safety of Medicines; CSM) established a register of adverse reactions. Since then 513 reports of drug-induced fatal aplastic anaemia or agranulocytosis have been received. About half of these deaths were notified in copies of "draft entries" (derived from death certificates) that mentioned drugs as the cause of a fatal reaction, which are supplied routinely by the Office of Population Censuses and Surveys (OPCS). The remainder were reported by doctors or the pharmaceutical industry-for example, on the committee's yellow cards. The two drugs most frequently suspect are phenylbutazone (188 deaths) and oxyphenbutazone (62 deaths).

These reports cover only a proportion of the fatal druginduced dyscrasias that actually occur, and it was therefore decided to investigate all the fatal dyscrasias identified by the OPCS, using death certificates that did not mention drugs, to obtain more realistic estimates of drug-induced dyscrasias. Because of the difficulty in establishing causality in individual cases such estimates can only be approximate, but they might be a useful guide to doctors in choosing suitable treatment for individual patients. In addition, drug-induced deaths from 
blood dyscrasias that had been reported spontaneously to the CSM were analysed; statistics on prescribing were studied; and a questionnaire was sent to a sample of general practitioners who had prescribed phenylbutazone and oxyphenbutazone.

\section{Patients and methods}

DEATHS FROM BLOOD DYSCRASIAS NOT CERTIFIED AS BEING DRUG-INDUCED

Photocopies of the OPCS's draft entries, which include all the information given in a death certificate, were obtained for everyone who died in England and Wales from 1 October 1974 to 30 September 1975 with aplastic anaemia (ICD 284) or agranulocytosis (ICD 288) as an underlying or contributory cause of death. Death certificates that mentioned a drug were not included since they are sent routinely to the CSM and added to the committee's register of adverse reactions.

Three hundred and seventy-six draft entries were obtained. In $233(62 \%)$ the underlying cause of death was aplastic anaemia and in $17(4.5 \%)$ it was agranulocytosis. In the remaining 126 entries $(33.5 \%)$ one or other of these conditions contributed to death (table I)

TABLE I-Diseases certified as the underlying cause of death

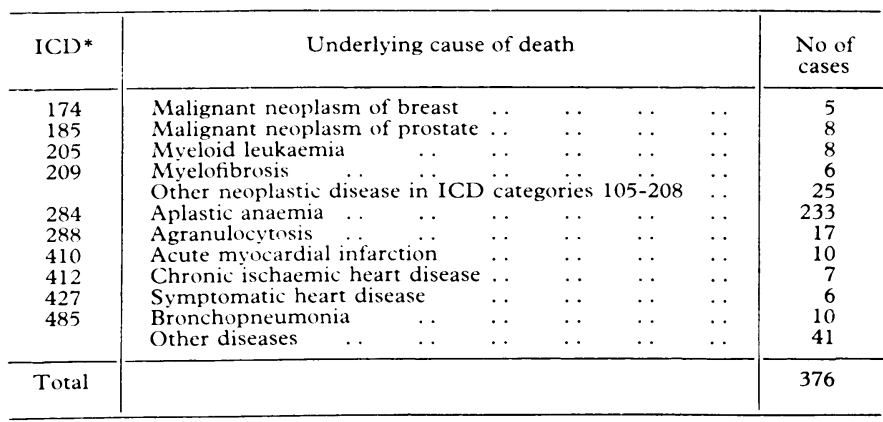

*IC.P."

The dead patients' doctors were identified by hospital medical record officers, coroners, or local family practitioner committees, and details of the medical history and drug treatment were obtained from them (through the committee's team of doctors working on a part-time basis and located in most parts of the country). When necessary, further information was obtained from hospital consultants.

One hundred and seven cases (28\% of the series) were excluded from the analysis because there was insufficient information $(11$ sets of notes could not be traced; five doctors refused to co-operate; 31 doctors could not be contacted; 17 interviews produced no information on the patient's condition or treatment before the diagnosis of the blood dyscrasia; and 43 interviews produced too little information to make an assessment). One patient on whom there was too little information was known to have received chloramphenicol and phenylbutazone before aplastic anaemia was diagnosed.

The remaining 269 patients identified from the death certificates were divided into five groups according to whether their blood dyscrasias were confirmed and, if so, whether they were related to drug treatment: group 1-dyscrasias not confirmed; group 2-dyscrasias secondary to other disease; group 3-dyscrasias unrelated to drug treatment; group 4-dyscrasias possibly related to drug treatment; group 5-dyscrasias probably related to drug treatment. The decision that a drug had been a probable, possible, or unlikely cause of the blood dyscrasia depended on the temporal relationship between drug administration and the onset of a dyscrasia and the presence or absence of other factors. ${ }^{1}$ The opinions of the consultant physicians and haematologists who had managed the patient were given considerable weight. Aplastic anaemia sometimes developed several months after exposure to the suspected precipitating agents had ceased; in other cases it developed insidiously after prolonged treatment; less often it had an acute onset, particularly when patients had been rechallenged with the same or a similar drug. Agranulocytosis, on the other hand, was usually more closely related to the drug exposure, developing in many cases within days rather than months. Any drug exposure in the 12 months before the onset of symptoms that led to a diagnosis of aplastic anaemia or in the three months before the onset of symptoms that lead to a diagnosis of agranulocytosis was considered to be a contributory factor. When more than 12 months had passed a causal relationship was considered to be unlikely.

\section{DEATHS REPORTED SPONTANEOUSLY TO THE COMMITTEE}

As a separate exercise 47 deaths due to blood dyscrasias that had been reported spontaneously to the committee were identified by a computer scan of the register of adverse reactions. Twenty-seven cases overlapped with those already described. Among the remaining 20 deaths five had been attributed to phenylbutazone and three to oxyphenbutazone.

\section{NHS PRICING BUREAU PRESCRIPTION DATA}

Data on the number of prescriptions for drugs identified in the first part of this study as being associated with blood dyscrasias and the total quantities prescribed by general practitioners in England and Wales were obtained from the quarterly tabulations of the NHS Pricing Bureau.

\section{OTHER DETAILS OF PRESCRIBING PRACTICE}

Details of the diagnosis, dose, and age and sex distribution in patients treated with phenylbutazone and oxyphenbutazone were supplied by Intercontinental Medical Statistics Limited (IMS). Further information about current prescribing practice was sought by a postal questionnaire. About a quarter of a million prescriptions written by a random sample of doctors during January 1976 were selected by the Pricing Bureau and sorted by hand. This identified 117 patients who had received oxyphenbutazone and 960 who had received phenylbutazone. Questionnaires were then sent to the 78 general practitioners who had prescribed oxyphenbutazone for the 117 patients and to 81 (every seventh doctor) who had prescribed phenylbutazone for 136 patients. (The sample did not include any doctors who had prescribed both drugs, and, to reduce the work load on individual doctors, the inquiry was limited to a maximum of four patients in any one practice.) The sample prescriptions were attached to the questionnaire and the doctor was asked to record the age and sex of the patient, the indication for treatment, the date of the first prescription, and details of subsequent courses of treatment up to January 1976.

\section{Results and comment}

GROUP 1

Twenty patients proved not to have had aplastic anaemia or agranulocytosis. Eight patients, all of whom had been treated with vitamin $B_{12}$, usually for long periods, had a final diagnosis of pernicious anaemia. One patient had received phenylbutazone for back pain and another oxyphenbutazone for neck pain. The remaining patients had suffered from various conditions and several were not anaemic when they died.

\section{GROUP 2}

Seventy patients had malignant disease: in 40 the malignant condition had been certified as the underlying cause of death; in five it was certified as a contributory cause; and in the remaining 25 the death certificate did not indicate that the patient had been suffering from a malignant condition. One other patient with systemic lupus erythematosus had developed aplastic anaemia after chemotherapy. A further patient had died from aplasia after ingesting hair dye. ${ }^{2}$

Eighteen patients in this group had developed aplastic anaemia as a result of cancer chemotherapy, but many more, especially those with leukaemia, would probably also have had chemotherapy. Once the investigator had established that the patient had a malignant condition, further details of the treatment that might have contributed to the aplasia were not sought.

Nine patients with aplastic anaemia associated with a malignant condition had received phenylbutazone or oxyphenbutazone before developing aplastic anaemia. In two cases the phenylbutazone was a more likely cause of the aplastic anaemia than the malignancy, while in three others it could reasonably be regarded as a possible cause. 
GROUP 3

Of the 59 patients with dyscrasias unrelated to drug treatment, two were infants, aged 8 months and 1 year, with idiopathic agranulocytosis. The remainder died from aplastic anaemia and included 31 females with a mean age of $52 \cdot 6$ years (range $4-89$ years) and 26 males with a mean age of 55.5 years (range 11-80). The pattern of age distribution (table II) differed from that among patients with probable or possible drug-related disease. The average age in both sexes was considerably less and there were two peaks in age distribution.

Three patients had been treated more than 12 months before the onset of symptoms with several courses of phenylbutazone and one had been treated with ibuprofen, but none had been rechallenged with either drug. Twenty-three had been treated with various drugs during the 12 months before the onset of symptoms, and 11 were taking them at the time of onset. None of the patients in this group was judged to have a drug-induced dyscrasia, though the possibility cannot be excluded.

\section{GROUP 4}

Thirty-four cases of aplastic anaemia and one case of agranulocytosis were considered to be a possible effect of drug treatment. This group included 19 women with a mean age of 71.5 years (range 16-93) and 16 men with a mean age of $66 \cdot 8$ years (range 23-91).

All the patients had received one or more of the suspect drugs in the 12 months before the onset of symptoms and 26 were still taking them at the time of onset. Fourteen patients had received non-steroidal anti-inflammatory agents over 12 months earlier (10 had received phenylbutazone, one oxyphenbutazone, three indomethacin, one gold, four ibuprofen, one mefenamic acid, and one naproxen). Three were still taking them (one phenylbutazone, one ibuprofen, and one naproxen) in the 12 months before the onset of anaemia in addition to other suspect drugs. In several cases the symptoms of anaemia may have actually been present earlier than had been recorded in the patients' notes. Various other drugs had been given, including oxytetracycline (6), co-trimoxazole (5), cyclopenthiazide (4), diazepam (4), paracetamol (4), frusemide (4), chlorpromazine (3), promethazine (3), and amitriptyline (3). Twenty-one other drugs had been taken by one or two patients.

\section{GROUP 5}

In 83 cases there was a probable causal relation with drug treatment. Many of these patients had been treated with non-steroidal antiinflammatory agents, especially phenylbutazone and oxyphenbutazone. These cases were divided into five subgroups according to the drugs implicated.

Phenylbutazone and oxyphenbutazone-Blood dyscrasias were thought to have been caused by phenylbutazone in 28 cases and by oxyphenbutazone in 11 cases. This group of patients contained a high proportion of elderly women (table II). Thirteen of the 39 death certificates gave no indication of the probable cause of the blood dyscrasia, but an earlier report had been submitted independently to the committee. The most commonly used dose of both drugs was one 100-mg tablet three times daily (table III). Twenty patients on phenylbutazone and 11 on oxyphenbutazone had taken the drug up to the time of onset of symptoms of anaemia. In the remainder, with one possible exception, there was an interval of two weeks to six months between the last recorded prescription and the onset of
TABLE III-Daily dose of phenylbutazone or oxyphenbutazone taken by patients in group 5

\begin{tabular}{|c|c|c|c|c|c|c|}
\hline Daily dose (mg): & 200 & 300 & 400 & 600 & 800 & $\begin{array}{l}\text { Not recorded } \\
\text { or variable }\end{array}$ \\
\hline $\begin{array}{l}\text { Phenylbutazone .. } \\
\text { Oxyphenbutazone.. }\end{array}$ & $\begin{array}{l}7 \\
1\end{array}$ & $\begin{array}{r}14 \\
8\end{array}$ & 2 & 1 & 1 & 5 \\
\hline
\end{tabular}

symptoms. In one case the doctor was virtually certain that the patient had retained some of her tablets for several months and then treated herself shortly before the blood dyscrasia started. The total periods of exposure are shown in table IV. General practitioners' notes did not always record precisely the condition being treated, although there was usually an adequate record of the prescriptions that had been written. Only two patients had a clearly defined history of rheumatoid arthritis. Other indications were gout in two patients, phlebitis in one patient, and a sprained ankle in another. The latter was a 43year-old man who developed aplasia after taking only 14 tablets of oxyphenbutazone. The other patients had been treated for osteoarthritis, low back pain, or various chronic or recurrent musculoskeletal disorders. The distribution of the specified indications resembled those shown in the IMS sample for phenylbutazone, which included rheumatoid arthritis $(5 \%)$, gout $(4 \%)$, phlebitis $(8 \%)$, and sprains $(5 \%)$. Similar proportions were shown in the smaller IMS sample for oxyphenbutazone, although use for sprains was rather higher $(10 \%)$. The results of the postal survey were similar and no differences were apparent between the distribution of indications for phenylbutazone and oxyphenbutazone; they included rheumatoid arthritis $(5 \%)$, gout $(3 \%)$, thrombophlebitis $(7 \%)$, and injuries $(14 \%)$.

TABLE IV-Duration of exposure to phenylbutazone or oxyphenbutazone by patients in group 5 (timed from date of first prescription; in many cases treatment was not continuous)

\begin{tabular}{l|c|c|c|c|c|c}
\hline $\begin{array}{c}\text { Total period of } \\
\text { exposure: }\end{array}$ & $\begin{array}{c}<1 \\
\text { Month }\end{array}$ & $\begin{array}{c}1-12 \\
\text { Months }\end{array}$ & $\begin{array}{c}1-3 \\
\text { Years }\end{array}$ & $\begin{array}{c}4-6 \\
\text { Years }\end{array}$ & $\begin{array}{c}7 \\
\text { Years }\end{array}$ & $\begin{array}{c}\text { Not } \\
\text { recorded }\end{array}$ \\
\cline { 2 - 6 } & 4 & 8 & 4 & 7 & 2 & 3 \\
\hline $\begin{array}{l}\text { Phenylbutazone } \\
\text { Oxyphenbutazone }\end{array}$ & 3 & 5 & 2 & & 1 & \\
\hline
\end{tabular}

History of treatment with phenylbutazone or oxyphenbutazoneSix patients had been treated earlier with phenylbutazone or oxyphenbutazone but developed a dyscrasia while being treated with other drugs. One had been exposed to aspirin, bendrofluazide, amitriptyline, perphenazine, and nitrazepam; two had been exposed to ibuprofen; two to indomethacin; and one (while living in South America) to dipyrone. Marrow failure might have been a delayed effect of phenylbutazone or oxyphenbutazone treatment or attributable to the drugs taken more recently. In table II it has been attributed to the more recent drugs.

Anti-inflammatory agents other than phenylbutazone or oxyphenbutazone-The dyscrasias in these 12 patients were associated with indomethacin (in eight cases), naproxen (in two), ketoprofen (in one case), and cyclophosphamide (in one). In several of these cases other drugs may also have played a part; three patients had received concurrent treatment with frusemide, one with chlorpropamide, one with cyclopenthiazide, and one with methyldopa.

TABLE II-Sex and age distribution of patients in relation to probability of drug causation

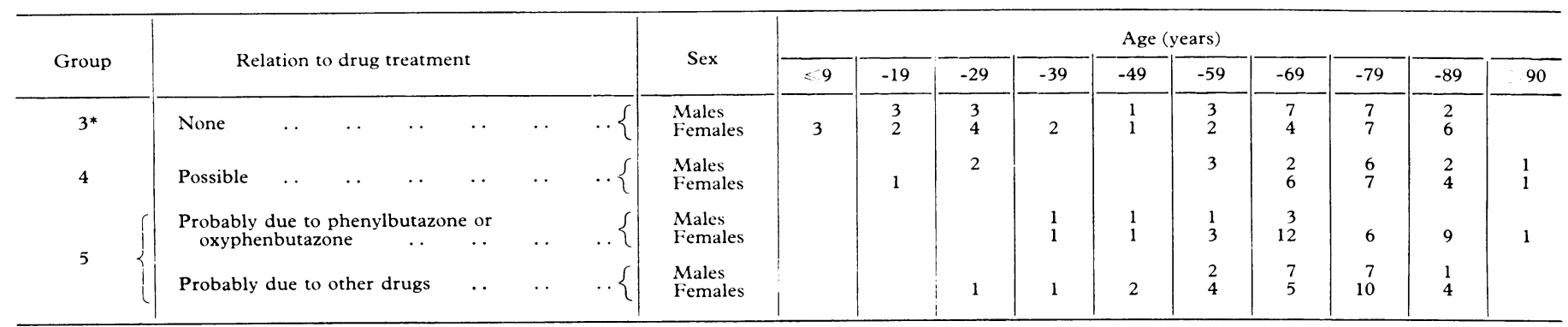

*The two infants in this group have been excluded from this table. 
Co-trimoxazole-Thirteen patients, six men and seven women aged 52 to 84 years, had been treated with co-trimoxazole, mostly for recurrent chest infections. Although the death certificate recorded aplastic anaemia as the cause of death in several cases, all had in fact developed selective neutropenia within a few days of starting treatment. Their deaths were due to agranulocytosis and several were only mildly anaemic at the time of death. Five of the 13 had received several courses of co-trimoxazole and one had been treated concurrently with nitrofurantoin. Only one of the 13 cases had been reported independently to the CSM.

Miscellaneous drugs-In the 13 remaining cases the suspect drugs included frusemide (2), chlorpromazine (2), acetazolamide (2), sulphasalazine (1), rifampicin (1), quinidine (1), methyldopa (1), hydrochlorothiazide (1), cyclophosphamide (1), and chlorpropamide (1).

\section{CASES REPORTED SPONTANEOUSLY TO CSM}

Twenty-seven of the 47 fatal blood dyscrasias reported to the committee during the study year (1 October 1974 to 30 September 1975) related to cases already included in the principal study. Although a drug reaction had been suspected and reported to the committee it had not been notified on the death certificate, which was therefore included among those provided for this study by the OPCS. Eight of the remaining 20 cases were notified by the OPCS on death certificates citing a drug as a cause of a fatal blood dyscrasia and the remainder were notified in other ways. In three cases death from aplastic anaemia was associated with the use of cyclophosphamide, methotrexate, or chlorambucil for malignant disease. In five cases aplastic anaemia had been attributed to phenylbutazone and in three to oxyphenbutazone; four and one of these cases respectively were thought, according to the criteria of the main study, to be directly related to the use of these drugs. One death was suspected to be due to the combination of indomethacin and ibuprofen in a patient previously treated with phenylbutazone. One patient died of agranulocytosis due either to indomethacin or procainamide and another to agranulocytosis due either to indomethacin or penicillamine. In the remaining nine cases death had been attributed to various drugs including phenothiazines (3), chloramphenicol (2), co-trimoxazole (1), carbimazole (1), a combination of amitriptyline and diazepam (1), and a combination of bumetanide, hydroflumethiazide, rauwolfia, and oxethazaine (1). One of the two deaths due to chloramphenicoloccurred in a 5-year-old girl who had been treated in Turkey and then flown to the United Kingdom. The other was an elderly man with bronchiectasis. His death was the first to be reported to the committee since its statement about the dangers of chloramphenicol was published in 1964." Before that time about one death caused by this drug had been reported each month in the United Kingdom.

The four deaths due to phenylbutazone and the one death due to

TABLE $\mathrm{v}-$ Details of patients identified in prescription samples

\begin{tabular}{|c|c|c|c|c|c|}
\hline & & \multicolumn{2}{|c|}{ Oxyphenbutazone } & \multicolumn{2}{|c|}{ Phenylbutazone } \\
\hline & & Men & Women & Men & Women \\
\hline \multirow[t]{2}{*}{$\begin{array}{l}\text { No of patients } \ldots \\
\text { Mean age (years).. } \\
\text { No }\left({ }_{0}\right) \text { treated for first time }\end{array}$} & $\because$ & $\begin{array}{r}35 \\
52 \cdot 7 \\
20(57) \\
\end{array}$ & $\begin{array}{r}57 \\
58 \cdot 6 \\
38(67) \\
\end{array}$ & $\begin{array}{r}44 \\
51 \cdot 4 \\
27(61) \\
\end{array}$ & $\begin{array}{r}74 \\
57 \cdot 2 \\
29(39) \\
\end{array}$ \\
\hline & & \multicolumn{2}{|c|}{ (63) } & \multicolumn{2}{|c|}{$(47)$} \\
\hline $\begin{array}{l}\text { Mean daily dose }(\mathrm{mg}) \\
\text { Mean period covered (years) }\end{array}$ & $\begin{array}{l}. \\
.\end{array}$ & $\begin{array}{l}360 \\
19 \cdot 4\end{array}$ & $\begin{array}{l}337 \\
21 \cdot 8\end{array}$ & $\begin{array}{l}324 \\
18 \cdot 2\end{array}$ & $\begin{array}{l}324 \\
22 \cdot 4\end{array}$ \\
\hline
\end{tabular}

oxyphenbutazone identified in this phase of the study brought the total number of deaths regarded as probably caused by these two drugs to 32 and 11 respectively. To interpret these figures in terms of risk, we need to know the numbers of patients treated with these drugs.

\section{SURVEY OF PRESCRIPTIONS FOR OXYPHENBUTAZONE AND PHENYLBUTAZONE}

One hundred and thirty-seven of the 159 doctors $(86 \%)$ returned questionnaires providing information about 92 of the 117 patients $(79 \%)$ who took oxyphenbutazone and 118 of the 136 patients $(87 \%)$ who took phenylbutazone. The results of this survey are summarised in table $\mathrm{V}$. Women used both drugs more than men and were on average about six years older than the men. There were only minor differences in the mean daily dose and the duration of treatment. The number of women who had previously been treated with phenylbutazone was appreciably larger than that of men or of patients of both sexes treated with oxyphenbutazone. Most of the previously treated patients had had intermittent treatment; usually relatively short periods of exposure to either drug had been interspersed with much longer periods without treatment.

It was not possible, from the questionnaires, to measure the total period of exposure in all cases. The mean interval between the first and the sample prescription for the 62 patients previously treated with phenylbutazone was, however, 67 months compared with only 34 months for the 34 patients treated with oxyphenbutazone. When periods of continuous treatment up to the date of the sample prescription were recorded, those on phenylbutazone had 21 months (24 patients) compared with only 11 months for the 13 patients treated with oxyphenbutazone. Although phenylbutazone was marketed first, both drugs have been widely used in the United Kingdom for over 15 years.

The most important finding in this survey was that $63 \%$ of the patients on oxyphenbutazone were taking the drug for the first time, compared with $47 \%$ of those who were prescribed phenylbutazone.

\section{Discussion}

Prescribing statistics measure total use of a drug but not the number of patients exposed, and mortality rates can be calculated only on the basis of patient-months or patient-years of exposure to the drug. If the risk associated with the use of a drug does not change during the course of treatment, this method of measurement may be useful for therapeutic decision-making. On the other hand, if the reactions are due to hypersensitivity or idiosyncrasy, such figures are quite inadequate. We need to know the number of deaths and the actual number of patients treated. This is especially important when considering drugs such as phenylbutazone and oxyphenbutazone, which may be used effectively in the short-term treatment of conditions such as gout, thrombophlebitis, or sports injuries.

Estimates for prescriptions issued on FP10 forms during the study year and the year before it are shown in table VI. During this period sales of ibuprofen, ketoprofen, and fenoprofen rose progressively, those for indomethacin and oxyphenbutazone remained fairly stable, and sales of phenylbutazone fell slightly.

Table VII shows the total number of prescriptions for phenylbutazone and oxyphenbutazone issued in England and Wales, the estimated total exposure of patients (calculated on the basis

TABLE VI-Estimates of numbers of prescriptions issued by general practitioners in England and Wales in each quarter during the study period and the year preceding it

\begin{tabular}{|c|c|c|c|c|c|c|c|c|c|c|}
\hline & & & \multicolumn{8}{|c|}{ No of prescriptions in each quarter (thousands) } \\
\hline & & & $\begin{array}{c}\text { Oct-Dec } \\
1973\end{array}$ & $\begin{array}{c}\text { Jan-March } \\
1974 \\
\end{array}$ & $\begin{array}{c}\text { Apr-Jun } \\
1974\end{array}$ & $\begin{array}{c}\text { Jul-Sept } \\
1974 \\
\end{array}$ & $\begin{array}{c}\text { Oct-Dec } \\
1974\end{array}$ & $\begin{array}{c}\text { Jan-March } \\
1975\end{array}$ & $\begin{array}{l}\text { Apr-Jun } \\
1975\end{array}$ & $\begin{array}{c}\text { Jul-Sept } \\
1975\end{array}$ \\
\hline $\begin{array}{l}\text { Phenylbutazone } \\
\begin{array}{l}\text { Oxyphenbutazone... } \\
\text { Indomethacin }\end{array} \\
\text { Ibuprofen ... } \\
\begin{array}{l}\text { Naproxen } \\
\text { Ketoprofen }\end{array} \\
\text { Fenoprofen }\end{array}$ & $\begin{array}{l}\ldots \\
\cdots \\
\cdots \\
\cdots \\
\cdots\end{array}$ & $\begin{array}{l}\because \\
\because \\
\because \\
\because \\
\cdots \\
\cdots\end{array}$ & $\begin{array}{r}820 \\
135 \\
700 \\
360 \\
160 \\
15\end{array}$ & $\begin{array}{r}795 \\
130 \\
755 \\
430 \\
260 \\
75 \\
5\end{array}$ & $\begin{array}{r}860 \\
130 \\
755 \\
410 \\
175 \\
75 \\
15\end{array}$ & $\begin{array}{r}830 \\
130 \\
780 \\
435 \\
180 \\
80 \\
20\end{array}$ & $\begin{array}{r}770 \\
130 \\
740 \\
440 \\
155 \\
105 \\
20\end{array}$ & $\begin{array}{r}760 \\
120 \\
725 \\
445 \\
160 \\
120 \\
25\end{array}$ & $\begin{array}{r}795 \\
140 \\
780 \\
520 \\
205 \\
150 \\
30\end{array}$ & $\begin{array}{r}745 \\
115 \\
740 \\
515 \\
190 \\
140 \\
30\end{array}$ \\
\hline
\end{tabular}


TABLE VII-Estimates of mortality expressed as deaths per 100000 patient-years of treatment, based on average dose of $300 \mathrm{mg} /$ day

\begin{tabular}{l|c|c|c|c}
\hline & $\begin{array}{c}\text { Total No of } \\
\text { prescriptions* }\end{array}$ & $\begin{array}{c}\text { No of } \\
\text { patient-years }\end{array}$ & $\begin{array}{c}\text { No of } \\
\text { Deaths }\end{array}$ & $\begin{array}{c}\text { Death rate } \\
\text { per 100 000 } \\
\text { patient-years }\end{array}$ \\
\hline $\begin{array}{c}\text { Phenylbutazone } \\
\text { Oxyphenbutazone }\end{array}$ & $\begin{array}{r}3070000 \\
505000\end{array}$ & $\begin{array}{c}192000 \\
30000\end{array}$ & $\begin{array}{c}32 \\
12\end{array}$ & $\begin{array}{c}16 \cdot 6 \\
40 \cdot 0\end{array}$
\end{tabular}

* October 1974-September 1975 in England and Wales.

+Four deaths due to phenylbutazone and one death due to oxyphenbutazone that were reported spontaneously were added to patients in group 5 .

of the total number of tablets prescribed and assuming a daily dose of $100 \mathrm{mg}$ three times a day for both drugs), the number of deaths probably related to the drugs, and estimates of total mortality expressed as the rate per 100000 patient-years of treatment. The death rate was 16.7 per 100000 patient-years for phenylbutazone and 40.0 per 100000 patient-years for oxyphenbutazone.

At first sight phenylbutazone seems to carry a much lower risk than oxyphenbutazone. The histories of the dead patients and the results of a postal questionnaire, however, suggest that if the actual numbers of patients receiving treatment are considered, some of this difference may disappear. The total length of treatment of patients dying from aplasia induced by phenylbutazone was twice that of those dying after oxyphenbutazone treatment. The total period of exposure to phenylbutazone in patients thus treated in the prescription sample was also twice as long as that in those treated with oxyphenbutazone. These results suggest that relatively more patients were treated with oxyphenbutazone than with the same number of prescriptions for phenylbutazone. This interpretation is further supported by the observation that $63 \%$ of those receiving oxyphenbutazone were "new patients," compared with only $47 \%_{0}$ of those receiving phenylbutazone. Assuming that this proportion of new patients starting treatment each year has remained steady, the prescription estimates give a measure of patient turnover and, used in conjunction with the questionnaire results, provide rough estimates of the numbers of patients concerned. The number of patients taking phenylbutazone may be calculated as about $1440000(47 \%$ of 3070000$)$; with 32 deaths from aplastic anaemia the mortality is 2.2 per 100000 patients. The corresponding figures for oxyphenbutazone are: 318000 patients $(63 \%$ of 505000$), 12$ deaths, and a mortality of 3.8 per 100000 patients. Although the mortality for oxyphenbutazone is still somewhat higher than that for phenylbutazone, it would be unwise, in view of the small number of deaths due to oxyphenbutazone, to conclude that there is any real difference in mortality between those two drugs.

The position of the patient may be compared with that of an airline passenger who is more interested in the risk of failing to reach his destination than in accident figures which might be expressed as the rate per million hours of flying time or passenger- miles flown. When the numbers of patients rather than the total patient-years of exposure were used to calculate the mortality rates, the estimates suggested a level of risk which many patients suffering from painful illness would find acceptable. In view of the comparatively short period of exposure of most patients to phenylbutazone or oxyphenbutazone, this type of estimate may be more helpful than the, perhaps more frightening, estimates derived from prescription data that do not include the numbers of patients concerned.

The estimates shown in table VII do not include the patients in group 5 whose deaths were attributed to other antiinflammatory agents after earlier treatment with phenylbutazone or oxyphenbutazone, nor do they include patients whose deaths were possibly related to these two drugs but who were allocated to the other groups. Also $28^{\circ}{ }_{0}$ of the cases in the main study could not be followed up and these might have included some phenylbutazone- or oxyphenbutazone-induced aplasias. These estimates of mortality probably under-represent the actual risk, although they are much higher than others that have been widely quoted. For example, Wallerstein ${ }^{4}$ quoted an incidence of aplastic anaemia (fatal and non-fatal) due to oxyphenbutazone of only 1 in 124000 .

The large relative excess of elderly women in this series deserves special mention. The excess does not seem to be accounted for by greater use of phenylbutazone or oxyphenbutazone by this age group or by the fact that women tend to outlive men. Thus in table VIII the observed numbers of deaths in men and women over and under the age of 65 years are compared with (a) the number that would be expected on the basis of the relative use by patients in these age groups as shown in the sample provided by IMS, and $(b)$ the number expected on the basis of the Pricing Bureau sample. The two sets of figures show a striking similarity, and the most important difference between the observed and the expected numbers of deaths is among women aged 65 or over and treated with phenylbutazone. Conversely, there was a deficit of deaths among yourger women and an even greater deficit among younger men. The number of deaths due to oxyphenbutazone was too small for a realistic comparison, but the same trend is suggested. This greater relative risk in elderly patients confirms the view expressed by Fowler. ${ }^{5}$

The death rate due to phenylbutazone may be estimated for the separate age groups. Thus the rate is $0.5 / 100000$ for men aged under $65,1.3$ for men aged 65 or over, 1.2 for women under 65 , and 6.5 for those aged 65 or over (using IMS estimates). The suggestion that rheumatic disease may predispose to marrow failure is not supported by these results, but only a very small proportion of the patients had this diagnosis. When compared with other anti-inflammatory drugs prescribed to a similar extent, phenylbutazone and oxyphenbutazone clearly account for a disproportionately large number of fatal blood dyscrasias-probably over one-third of all drug-induced blood dyscrasias in the United Kingdom (excluding cancer chemotherapy). The doses used by patients who died did not seem to be

TABLE VIII-Comparison between observed and expected numbers of deaths according to sex and age

\begin{tabular}{|c|c|c|c|c|c|c|c|c|c|c|c|c|}
\hline & & & & & \multicolumn{4}{|c|}{ Phenylbutazone } & \multicolumn{4}{|c|}{ Oxyphenbutazone } \\
\hline & & & & & \multicolumn{2}{|c|}{ Observed deaths } & \multicolumn{2}{|c|}{ Expected deaths } & \multicolumn{2}{|c|}{ Observed deaths } & \multicolumn{2}{|c|}{ Expected deaths } \\
\hline & & & & & No & $\%$ & No* & $\% *$ & No & $\%$ & No* & $\% *$ \\
\hline \multicolumn{13}{|c|}{ Men } \\
\hline $\begin{array}{l}\text { Aged }<65 \\
\text { Aged } \geqslant 65\end{array}$ & $\because$ & $\therefore$ & $\ldots$ & $\ldots$ & $\begin{array}{l}2 \\
2\end{array}$ & $\begin{array}{l}6 \\
6\end{array}$ & $\begin{array}{l}9(9) \\
4(3)\end{array}$ & $\begin{array}{l}28(28) \\
12(9)\end{array}$ & $\begin{array}{l}1 \\
1\end{array}$ & $\begin{array}{l}8 \\
8\end{array}$ & $\begin{array}{l}4(3) \\
1(2)\end{array}$ & $\begin{array}{r}33(25) \\
8(17)\end{array}$ \\
\hline \multicolumn{13}{|c|}{ Women } \\
\hline $\begin{array}{l}\text { Aged }<65 \\
\text { Aged } \geqslant 65\end{array}$ & $\therefore$ & $\ldots$ & $\ldots$ & $\because$ & $\begin{array}{r}7 \\
21\end{array}$ & $\begin{array}{l}22 \\
66\end{array}$ & $\begin{array}{r}12(11) \\
7(9)\end{array}$ & $\begin{array}{l}38(34) \\
22(28)\end{array}$ & $\begin{array}{l}4 \\
6\end{array}$ & $\begin{array}{l}33 \\
50\end{array}$ & $\begin{array}{l}5(4) \\
2(3)\end{array}$ & $\begin{array}{l}42(33) \\
17(25)\end{array}$ \\
\hline All patients & .. & .. & .. & $\ldots$ & 32 & 100 & 32 & $100(100)$ & 12 & 100 & 12 & $100(100)$ \\
\hline
\end{tabular}

*Values are expected numbers calculated on basis of distribution of prescription sample by IMS. Figures in parentheses are calculated on basis of prescription sample obtained from the NHS Pricing Bureau. 
larger than those prescribed for patients in the prescription sample (none of the doctors reported serious side effects in the returned questionnaires).

No indication for treatment can be singled out as being associated with a particularly high risk. The distribution of indications among the fatal cases and in both prescription samples was very similar. The short-term use of phenylbutazone or oxyphenbutazone for post-traumatic pain, thrombophlebitis, or gout do not seem, on the basis of these results, to be particularly hazardous, although a very much larger series would have to be studied to be sure of this. The main concern, on the contrary, seems to be the use of these two drugs in elderly patients. Indomethacin and co-trimoxazole are appreciable subsidiary causes of blood dyscrasias, the latter being the most common cause of fatal agranulocytosis.

I thank the many general practitioners and consultants who provided the information essential to this inquiry and the doctors who conducted the interviews; the Office of Population Censuses and Surveys; Intercontinental Medical Statistics Limited; the Prescription Pricing Authority; the statistics and research division of the DHSS; and
Mrs Alice Renauld, who typed the manuscript. I am especially grateful to Sir Austin Bradford-Hill, Sir Richard Doll, Professor David Finney, Professor David Price Evans, and Professor Duncan Vere for their critical and most helpful advice in the preparation of this manuscript. Finally, I should like to record my debt to my friend the late Carl de Gruchy, who encouraged me to start this study, and who, most regrettably, did not live to see its conclusion.

\section{References}

1 de Gruchy, G C, Drug-Induced Blood Disorders. Oxford, Blackwell Scientific, 1975 .

2 Toghill, P J, and Wilcox, R G, British Medical fournal, 1976, 1, 502.

${ }^{3}$ Committee on Safety of Drugs, Chloramphenicol. (Adverse Reactions Series No 4). London, HMSO, 1967.

4 Wallerstein, R O, et al, fournal of the American Medical Association, 1969, 208, 2045.

${ }^{5}$ Fowler, P D, Annals of the Rheumatic Diseases, 1967, 26, 344

${ }^{6}$ International Classification of Diseases, 8th revision. Geneva, World Health Organisation, 1967.

\title{
Haemodynamic effects of beta-adrenergic blockade in hyperthyroid patients with and without heart failure
}

\author{
HAMID IKRAM
}

British Medical fournal, 1977, 1, 1505-1507

\section{Summary}

Haemodynamic studies were performed in 10 patients with uncomplicated thyrotoxicosis and seven with thyrotoxic cardiac failure. The cardiac output of those with uncomplicated hyperthyroidism was higher than normal at rest. After $2 \mathrm{mg}$ of intravenous propranolol there was a $13 \%$ fall but the level was still higher than normal. In patients with thyrotoxic cardiac failure the resting cardiac output was normal, but it fell after propranolol by $30 \%$ to subnormal levels.

In both groups there was an increase in right heart pressures and fall in the rate of increase in arterial pressure, which indicated a decrease in myocardial contractility.

These results indicate that increased autonomic activity is a compensatory phenomenon in hyperthyroid heart failure and that its abolition by beta-blocking drugs has a deleterious effect on cardiac function. They are therefore contraindicated in patients with thyrotoxic heart failure.

\section{Introduction}

Autonomic blockade has been advocated as a therapeutic measure in hyperthyroidism because many of the circulatory

\footnotetext{
Department of Cardiology, Princess Margaret Hospital, Christchurch, New Zealand

HAMID IKRAM, MD, FRCPED, consultant cardiologist
}

manifestations of hyperthyroidism resemble those of betasympathetic stimulation. Early workers using non-specific autonomic-blocking agents such as reserpine, ${ }^{1-3}$ methyldopa, ${ }^{4}$ and guanethidine, ${ }^{5-7}$ however, produced equivocal results. When specific beta-receptor antagonists became available they were tested in patients with hyperthyroidism, again with conflicting results. Parenteral administration of pronethalol, ${ }^{8}$ alprenolol, ${ }^{9}$ and sotalol $^{10}$ had no significant effect on most of the circulatory changes. Only intravenous propranolol consistently reduced heart rate and cardiac output. ${ }^{11-13}$ The doses used in these studies, however, are now regarded as cardiotoxic.

Not only is the question of the therapeutic benefit of betablockers in uncomplicated hyperthyroidism unresolved; there is also a lack of information on the effects of beta-blockers in thyrotoxic heart failure. Some workers, extrapolating from observations in uncomplicated hyperthyroidism, have stated that these drugs are beneficial in thyrotoxic heart failure. ${ }^{13} 14$ A survey of reports published in English has, however, failed to show a single study of the effects of beta-blockade in heart failure due to hyperthyroidism.

This study was therefore performed to assess the haemodynamic changes produced by beta-adrenergic blockade in thyrotoxic patients with and without cardiac failure.

\section{Patients and methods}

Seventeen patients were studied. Ten had uncomplicated thyrotoxicosis and seven suffered from thyrotoxic cardiac failure. The diagnosis of hyperthyroidism was based on a suggestive history together with positive radioactive iodine uptake and protein-bound iodine values.

The patients with thyrotoxicosis and heart failure had been extensively screened to exclude any coexisting cardiac disease. Patienfs with a history of cardiac pain or electrocardiographic evidence ot old infarction were excluded from the study. Those with diastolic arterial pressures of over $100 \mathrm{~mm} \mathrm{Hg}$ or with clinical evidence of 